\title{
外源褪黑素对干旱胁迫下大豆鼓粒期生理和产量的影响
}

\section{邹京南于奇金喜军王明瑶秦彬任春元王孟雪 张玉先*}

黑龙江八一农垦大学农学院, 黑龙江大庆 163319

摘 要: 干旱胁迫降低大豆产量, 探究提高大豆耐旱能力和降低产量损失的机制对大豆生产具有重要意义。施褪黑 素能缓解干旱胁迫对植株生长的抑制和氧化损伤。本试验于 2017-2018 年研究叶面喷施褪黑素对干旱胁迫下大豆鼓 粒期叶片光合、抗逆、碳氮代谢和产量的影响表明, 外源褪黑素提高干旱胁迫下大豆叶片抗氧化酶活性, 抑制活性氧 的产生和细胞膜损伤, 缓解干旱胁迫对光合能力的抑制, 提高碳氮同化能力, 最终缓解干旱胁迫造成的产量损失。与 干旱胁迫相比, 褪黑素处理下单株荚数、单株粒数和百粒重两年平均提高了 $2.9 \% 、 0.8 \%$ 和 $17.2 \%$, 产量(单株粒重) 平均提高了 $14.7 \%$ 。

关键词: 褪黑素; 大豆; 干旱; 光合; 抗氧化系统; 碳氮代谢; 产量

\section{Effects of exogenous melatonin on physiology and yield of soybean during seed filling stage under drought stress}

\author{
ZOU Jing-Nan, YU Qi, JIN Xi-Jun, WANG Ming-Yao, QIN Bin, REN Chun-Yuan, WANG Meng-Xue, and \\ ZHANG Yu-Xian*
}

College of Agronomy, Heilongjiang Bayi Agricultural University, Daqing 163319, Heilongjiang, China

\begin{abstract}
Drought stress reduces soybean yield. Exploring the mechanism of improving drought tolerance and reducing yield loss is of great significance for soybean production. Melatonin application can alleviate the growth inhibition and oxidative damage of plants under drought stress. In this experiment, the effects of foliar application of melatonin on photosynthesis, stress resistance, carbon and nitrogen metabolism and yield of soybean during seed filling stage under drought stress were studied in 2017-2018. The application exogenous melatonin increased the antioxidant enzyme activity, inhibited the production of reactive oxygen species, decreased cell membrane damage under drought stress, alleviated the inhibition of photosynthetic capacity by drought stress, improved the carbon and nitrogen assimilation ability, and alleviated the yield loss caused by drought stress. Compared with drought stress, the treatment of melatonin increased the number of pods per plant, the grain number per plant and the hundred grain weight by $2.9 \%, 0.8 \%$, and $17.2 \%$ on average of two years, respectively, and the yield (grain weight per plant) increased by $14.7 \%$.
\end{abstract}

Keywords: melatonin; soybean; drought; photosynthesis; antioxidant system; carbon and nitrogen metabolism; yield

大豆是我国重要的油料作物, 因干旱导致产量 损失达 $25 \% \sim 50 \%{ }^{[1]}, 2018$ 年 8 月辽宁沈阳和吉林公 主岭地区遭遇因高温少雨引起的大面积干旱, 产量
较 2017 年减少三成。大豆对干旱胁迫的最敏感时期 是在开花期后 ${ }^{[2]}$, 鼓粒期是大豆子粒发育和产量形 成的关键时期, 也是碳氮同化和转移生理代谢最复

\footnotetext{
本研究由国家重点研发计划项目(2018YFD0201000), 国家现代农业产业技术体系建设专项(CARS-04-01A), 黑龙江省自然科学基金项 目(C2017049)，黑龙江省农星总局重点科研计划项目(HNK135-02-06)和国家重点研究开发项目子课题“东北地区抗旱灌溉与优质高产 春大豆关系的研究”项目(2018YFD1000905)资助。

This study was supported by the National Key R\&D Program (2018YFD0201000), the China Agricultural Research System (CARS-04-01A), the Natural Science Foundation of Heilongjiang Province (C2017049), the Heilongjiang Provincial Land Reclamation Bureau Key Research Project (HNK135-02-06), and the National Key Research and Development Project Sub-Project: Research on the Relationship between Drought-Resistant Irrigation and High-Quality and High-Yield Spring Soybean in Northeast China (2018YFD1000905).

*通信作者(Corresponding author): 张玉先, E-mail: zyx_1xy@126.com

第一作者联系方式: E-mail: zoujingnan222@163.com
}

Received (收稿日期): 2019-08-01; Accepted (接受日期): 2019-12-26; Published online (网络出版日期): 2020-01-14.

URL:http://kns.cnki.net/kcms/detail/11.1809.S.20200113.1712.004.html 
杂阶段, 随着鼓粒期进程, 大豆植株生理活性由旺 盛逐渐变弱, 直至成熟。在此过程中, 不仅新同化 的光合产物向子粒运输, 储存在营养器官中的同化 物也由源(营养器官)向库(子粒)转移 ${ }^{[3]}$, 此阶段发 生干旱胁迫势必对同化产物的形成和转运产生不 利影响, 导致产量降低 ${ }^{[4]}$ 。干旱胁迫还会降低大豆 叶片光合能力, 导致电子传输链过度还原, 导致光 氧化 ${ }^{[5]}$ ，产生 $\operatorname{ROS}^{[6]}$ 。ROS 过度积累会损伤膜系统， 引起蛋白质降解、DNA 损伤。植物自身通过调节 抗氧化系统来应对氧化损伤, 如提高抗氧化酶活性 和抗氧化剂含量, 同时通过提高诸如庶糖等一些代 谢酶活性, 增加可溶性糖、可溶性蛋白、脯氨酸含 量等来减少细胞水分流失以及维持细胞膜结构稳 定性 ${ }^{[7-10]}$ 。这在短期或轻度干旱胁迫下能维持熫糖 含量为植物生长发育提供能量, 但氮同化能力会显 著下降, 抑制蛋白质合成及光合产物的转运能力, 若干旱胁迫时间延长, 子粒则会停止生长甚至植株 死亡 ${ }^{[11-12]}$ 。

施植物生长调节剂是增强作物抗旱性的重要手 段之一 ${ }^{[13]}$ 。褪黑素(melatonin)在植物抵御非生物胁 迫中发挥着重要保护作用 ${ }^{[14]}$ 。近年来, 褪黑素在植 物抗旱方面的研究取得了一定进展。外源褪黑素处 理可提高干旱胁迫下玉米幼苗抗氧化酶活性 ${ }^{[15]}$; 缓解干旱胁迫对光合系统的损伤 ${ }^{[16]}$; 降低干旱胁 迫下小麦中 MDA、ROS 含量, 提高谷胱甘肽 ASA 和 GSH 含量 ${ }^{[17-18]}$, 促进番茄 ASA-GSH 循环中 APX 和 GR 等活性的增加 ${ }^{[19]}$, 减缓干旱胁迫造成的氧化 损伤。另外, 褪黑素处理可促进干旱胁迫下大豆叶 片脯氨酸、可溶性糖和可溶性蛋白含量增加并增加 产量 ${ }^{[20]}$ 。

大豆是共生固氮作物, 对碳氮代谢能力要求较 高, 而关于外源褪黑素对干旱胁迫条件下大豆碳氮 代谢相关方面的研究未见报道。因此, 本试验研究 外源褪黑素在干旱胁迫条件下对大豆鼓粒期生理变 化的影响, 以及对产量损失缓解程度, 以期为其实 际应用提供一定研究基础和理论指导。

\section{1 材料与方法}

\section{1 试验材料和设计}

大豆品种绥农 26 号, 由国家杂粮工程技术研究 中心提供。褪黑素(meltaionin)购自 Sigma 试剂公司。 以预备试验确定处理浓度为 $100 \mu \mathrm{mol} \mathrm{L}^{-1}$ 。

试验于 2017-2018 年在黑龙江八一农星大学国
家杂粮工程技术研究中心试验基地进行, 将大豆种 子用 $5 \%$ 次氯酸钠 $(\mathrm{w}: \mathrm{v})$ 消毒 $3 \mathrm{~min}$ 并用蒸馏水洗净, 在发芽盒 $22^{\circ} \mathrm{C}$ 暗发芽 $1 \mathrm{~d}$ 。挑选芽长约 $1 \mathrm{~cm}$ 幼芽用 于盆栽, 每盆 3 株。

盆栽所用白色塑料桶高 $0.33 \mathrm{~m}$, 直径 $0.3 \mathrm{~m}$, 桶 底均钻 3 个 $1 \mathrm{~cm}$ 直径小孔。在桶底铺一层纱网。培 养土按珍珠岩：蛭石：黑钙土 1：3：12(v：v：v) 的比例混合, 每桶装 $16 \mathrm{~kg}$; 培养土 2017 年含碱解氮 $96.3 \mathrm{mg} \mathrm{kg}^{-1}$ 、速效磷 $22.7 \mathrm{mg} \mathrm{kg}^{-1}$ 、速效钾 $69.7 \mathrm{mg}$ $\mathrm{kg}^{-1}$ 、有机质 $11.5 \mathrm{mg} \mathrm{kg}^{-1}, \mathrm{pH}$ 7.8, 田间持水量 46.1\%; 2018 年含碱解氮 $72.1 \mathrm{mg} \mathrm{kg}^{-1}$ 、速效磷 $14.1 \mathrm{mg} \mathrm{kg}^{-1}$ 、 速效钾 $173.0 \mathrm{mg} \mathrm{kg}^{-1}$ 、有机质 $3.9 \mathrm{mg} \mathrm{kg}^{-1}, \mathrm{pH} 7.1$, 田 间持水量 $50 \%$ 。

维持 $80 \%$ 田间持水量至大豆生长至鼓粒初期 (R5 期, 倒数第 4 个豆荚籽粒约 $3 \mathrm{~mm}$ ), 设置旱胁迫 处理(D)、干旱胁迫下喷施褪黑素处理 $(M T+D) 、$ 正 常供水对照(WW) 3 个处理, 每个处理 30 盆。(1)干 旱胁迫处理(D)在大豆生长至鼓粒期开始停止供水, 通过称重法控制土壤含水量(开始控水当天记为第 1 天, 每晚 8 时叶片喷施清水连续喷施 $5 \mathrm{~d}$ ), 使土壤含 水量逐渐达到田间持水量的 $50 \%$ 取第 1 次样(2017 年停止供水 $10 \mathrm{~d}$ 达到 $50 \%$ 田间持水量; 2018 年停止 供水 $8 \mathrm{~d}$ 达到 $50 \%$ 田间持水量, 维持此含水量到达处 理第 10 天取第 1 次样), 之后维持 $50 \%$ 田间持水量在 处理第 17 天和第 24 天分别做第 2 次和第 3 次取样, (2)干旱胁迫下喷施褪黑素处理 $(\mathrm{MT}+\mathrm{D})$ 在停止供水 当天叶片喷施 $100 \mu \mathrm{mol} \mathrm{L}^{-1}$ 裉黑素溶液连续喷施 $5 \mathrm{~d}$, 控水标准、复水时间和取样与 $\mathrm{D}$ 处理一致, 之后恢 复正常供水成熟期测产。(3)土壤含水量始终保持田 间持水量 $80 \%$ 作为正常供水对照 $(\mathrm{WW})$; 处理第 1 天 开始叶面喷施清水, 连续喷施 $5 \mathrm{~d}$, 取样同 $\mathrm{D}$ 和 $\mathrm{MT}+\mathrm{D}$ 。

\section{2 测定项目和方法}

1.2.1 大豆叶片光合特性参数、叶绿素荧光参数和 Rubisco 酶活性测定 光合特性参数使用( $\mathrm{Li}-6400$; Li-Cor, Huntington Beach, CA, USA)光合仪测定大豆 叶片净光合速率 $\left(P_{\mathrm{n}}\right)$ 、气孔导度 $\left(G_{\mathrm{s}}\right)$ 、蒸腾速率 $\left(T_{\mathrm{r}}\right)$ 、 胞间 $\mathrm{CO}_{2}$ 浓度 $\left(C_{\mathrm{i}}\right)$, 水分利用率 $(\mathrm{WUE})=P_{\mathrm{n}} / T_{\mathrm{r}}$ 。测定 光强为 $1200 \mu \mathrm{mol} \mathrm{m} \mathrm{m}^{-2} \mathrm{~s}^{-1}, \mathrm{CO}_{2}$ 供应浓度为 $400 \mu \mathrm{mol} \mathrm{mol}{ }^{-1}$, 叶片温度 $25^{\circ} \mathrm{C}$, 相对湿度约为 $25 \%$; 使用叶绿素荧光仪(FMS-2, Hansatech, England)测量 叶绿素苂光参数, 即大豆倒数第 2 片功能叶 PSII 的 最大光化学效 $F_{\mathrm{v}} / F_{\mathrm{m}}$, PSII 的量子产额 $\left(\Phi_{\mathrm{PSII}}\right)$, 光化 
学猝灭系数 $\left(q_{\mathrm{N}}\right)$ 非光化学猝灭系数 (NPQ), 最大光能 转化潜力 $\left(F_{\mathrm{v}} / F_{\mathrm{o}}\right)$, 表观光合电子传递速率(ETR)。将 冷冻的叶片在液氮中研磨成匀浆, 用 $2 \mathrm{~mL}$ 含有 $50 \mathrm{mmol} \mathrm{L}^{-1}$ BICINE, N,N-二羟乙基甘氨酸、 $\mathrm{pH} 8.0$ 的 $20 \mathrm{mmol} \mathrm{L}^{-1} \mathrm{MgCl}_{2} 、 2 \mathrm{mmol} \mathrm{L}^{-1}$ 苯基甲磺酰氟、

$50 \mathrm{mmol} \mathrm{L}{ }^{-1}$ 2-颈基乙醇和 $30 \mathrm{mg}$ 聚乙烯基聚吡咯烷 酮(PVPP)的溶液通过离心 $\left(10,000 \times g, 4^{\circ} \mathrm{C}, 2 \mathrm{~min}\right)$ 提 取上清液, 根据 Parry 等 ${ }^{[21]}$ 的方法计算 Rubisco 羧化 酶活性。

1.2 .2 抗氧化能力和膜脂过氧化程度测定参照 Zou 等 ${ }^{[20]}$ 方法测定超氧化物歧化酶(SOD)活性、过氧 化物酶(POD)活性、过氧化氢酶(CAT)活性、抗坏血 酸过氧化物酶(APX)活性, 参照 Kumar 等 ${ }^{[22]}$ 的方法 测定丙二醛(MDA)含量, 参照 $\mathrm{Su}$ 等 ${ }^{[23]}$ 方法测定 $\mathrm{H}_{2} \mathrm{O}_{2}$ 含量, 参照 $\mathrm{Ke}$ 等 ${ }^{[24]}$ 方法测定超氧阴离子产生 速率。用电导率仪(DDS-309C, ARK Instruments, Chengdu, China) 测量叶片相对电导率。根据 Shan 和 $\mathrm{Liang}^{[25]}$ 方法测定单脱氢抗坏血酸还原酶 (MDHAR)、脱氢抗坏血酸还原酶(DHAR), 根据 Loggini 等 ${ }^{[26]}$ 方法测定谷胱甘肽还原酶 $(G R)$ 、谷胱甘 肽过氧化物酶(GPX), 根据 $\mathrm{Li}$ 等 ${ }^{[27]}$ 方法测定谷胱甘 肽(GSH)和抗坏血酸(ASA)含量。

\subsection{3 碳氮代谢相关测定参照徐光龙 ${ }^{[28]}$ 方法} 测定硝酸还原酶(NR)活性, 参照屈春媛等 ${ }^{\left[{ }^{[29}\right.}$ 的方法 测定谷氨酰胺合成酶 (GS)活性、谷氨酸合酶(GOGAT) 活性和谷氨酸脱氢酶 (GDH) 活性, 根据 Oliveira 等 ${ }^{[30]}$ 方法测定 $\mathrm{NH}_{4}{ }^{+}$(铵态氮) 和 $\mathrm{NO}_{3}{ }^{-}$(硝态氮) 含量。参照 张志良 ${ }^{[11}$ 方法测定可溶性糖、蔗糖、果糖和淀粉含 量, 参照 Chopra 等 ${ }^{[32]}$ 方法测定蔗糖合成酶(SPS)和 熫糖磷酸合成酶(SS)活性。参考 Tsai 等 ${ }^{[33]}$ 方法测定 酸性转化酶(AI)和中性转化酶(NI)活性。

\subsection{4 产量相关参数测定 在 2017-2018 年成} 熟期选取每个处理 10 盆, 测量单株荚数、单株粒数、 单株粒重和百粒重, 计算产量缓解率和减产率。选 用 2018 年相关生理指标测量测定值。

\section{3 数据处理}

采用 Microsoft Excel 2010 处理数据, 并用 SPSS 20.0 软件统计分析, 用 Origin 2017 作图。

\section{2 结果与分析}

2.1 外源褪黑素对干旱胁迫下大豆光合特性和

Rubisco 活性的影响

与正常供水相比, 干旱胁迫降低了大豆叶 $P_{\mathrm{n}}$
(图 1-A)、G $G_{\mathrm{s}}$ (图 1-B)、 $T_{\mathrm{r}}$ (图 1-C)和 Rubisco 活性 (图 1-F), 并随着干旱胁迫的延长, 抑制作用越明显; 干旱胁迫提高了 WUE (图 1-E), 并随干旱胁迫时间 延长呈升降升趋势; 在干旱胁迫第 10 天和第 17 天 降低了 $C_{\mathrm{i}}$ (图 1-D), 胁迫至第 24 天 $C_{\mathrm{i}}$ 有所升高。裉 黑素处理可以提高干旱胁迫下 $P_{\mathrm{n}} 、 G_{\mathrm{s}} 、 T_{\mathrm{r}}$ 和 Rubisco 活性，分别增加了 $19.4 \% \sim 44.1 \% 、 9.6 \% \sim 32.5 \%$ 、 $22.6 \% \sim 42.7 \%$ 和 $9.6 \%$ 27.8\%。褪黑素处理降低了干 旱胁迫下第 10 天和第 24 天 WUE，增加了第 17 天 WUE。褪黑素处理提高了干旱胁迫第 10 天和第 17 天 $C_{\mathrm{i}}$, 降低了第 24 天 $C_{\mathrm{i}}$ 。

2.2 外源裉黑素对干旱胁迫下大豆叶绿素苂光 参数的影响

与正常供水相比, 干旱胁迫降低了 $F_{\mathrm{v}} / F_{\mathrm{m}}$ (图 2-A)、 $q_{\mathrm{N}}$ (图 2-B)、ETR (图 2-C)、 $\Phi_{\mathrm{PSII}}$ (图 2-E) 和 $F_{\mathrm{v}} / F_{\mathrm{o}}$ (图 2-F), 且干旱胁迫的延长抑制作用越明 显; NPQ (图 2-D) 随着干旱胁迫的延长而不断上升。 褪黑素处理可以缓解干旱胁迫对 $F_{\mathrm{v}} / F_{\mathrm{m}} 、 F_{\mathrm{v}} / F_{\mathrm{o}} 、 q_{\mathrm{N}}$ 、 ETR 和 $\Phi_{\mathrm{PSII}}$ 的抑制; 还能缓解 NPQ 的上升。与干 旱胁迫相比, 褪黑素处理下 $F_{\mathrm{v}} / F_{\mathrm{m}} 、 F_{\mathrm{v}} / F_{\mathrm{o}} 、 q_{\mathrm{N}} 、 \mathrm{ETR}$ 和 $\Phi_{\mathrm{PSII}}$ 分别提高了 $3.2 \% \sim 6.1 \% 、 6.8 \% \sim 19.8 \%$ 、 $5.4 \% \sim 12.4 \% 、 5.6 \% \sim 30.7 \%$ 和 $7.5 \% \sim 15.9 \%$, NPQ 降低 了 $5.7 \% \sim 20.8 \%$ 。

\section{3 外源褪黑素对干旱胁迫下大豆碳代谢的影响}

与正常供水相比, 干旱胁迫增加了 SPS (图 3-A)、

SS (图 3-B)、AI (图 3-C)和 NI (图 3-D)的活性, 随着 干旱胁迫的延长, 呈现先上升后下降趋势。干旱胁 迫增加了可溶性糖(图 3-E)、蔗糖(图 3-H)和果糖含 量(图 3-G)并降低淀粉含量(图 3-F), 随着干旱胁迫 的延长, 蔗糖、果糖和可溶性糖含量呈先上升后下 降趋势, 淀粉含量呈不断下降趋势。褪黑素处理提 高了干旱胁迫下可溶性糖、蔗糖、果糖含量和 SPS、 SS、AI、NI 活性，降低淀粉含量。与干旱胁迫相比, 褪黑素处理下可溶性糖、蔗糖和果糖含量分别增加 9.8\% 23.5\%、14.7\% 21.5\%和 $24.7 \% \sim 26.8 \%$ ，淀粉含 量下降 $10.2 \% \sim 18.00 \%$, SPS、SS、AI 和 NI 活性分别 增加 $4.3 \% \sim 19.1 \% 、 8.2 \% \sim 21.5 \% 、 11.6 \% \sim 15.8 \%$ 和 $6.3 \% \sim 42.5 \%$ 。

\section{4 外源褪黑素对干旱胁迫下大豆氮代谢的影响}

与正常供水相比, 干旱胁迫增加了 $\mathrm{NH}_{4}^{+}$(图 4-A) 和 $\mathrm{NO}_{3}{ }^{-}$(图 4-B)的含量, 且随着干旱胁迫的延长呈 先上升后下降趋势。干旱胁迫降低了 GS (图 4-D)和 $\mathrm{GDH}$ (图 4-E)活性, 且随着干旱胁迫的延长呈不断 


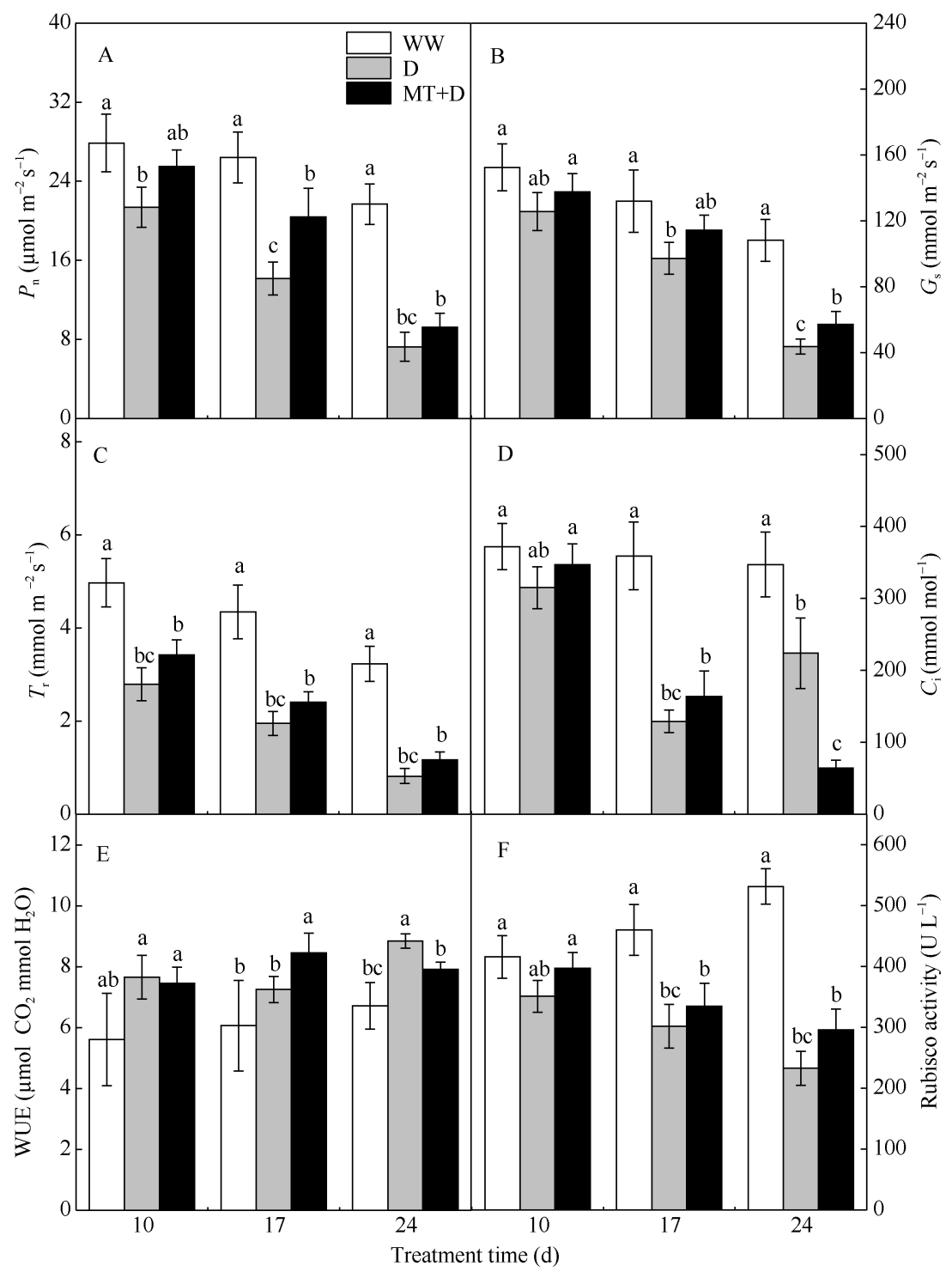

图 1 外源褪黑素对干旱胁迫下大豆鼓粒期叶片光合参数和 Rubisco 活性的影响

Fig. 1 Effect of exogenous melatonin on photosynthetic parameters and Rubisco activity of soybean during seed filling stage under drought stress

A：净光合速率; B：气孔导度; C: 蒸腾速率; D: 胞间二氧化碳浓度; E：水分利用率; F：核酮糖-1,5-二磷酸羧化酶。WW：鼓粒期开始 保持 $80 \%$ 田间持水量叶片喷施 $5 \mathrm{~d}$ 清水对照; D: 鼓粒期开始停止供水保持 $50 \%$ 田间持水量叶片喷施 $5 \mathrm{~d}$ 清水干旱胁迫处理; MT $+\mathrm{D}$ : 鼓 粒期开始停止供水保持 $50 \%$ 田间持水量叶片喷施 $5 \mathrm{~d} 100 \mu \mathrm{mol} \mathrm{L} \mathrm{L}^{-1}$ 裉黑素加干旱胁迫处理。10: 不同处理 $10 \mathrm{~d}$ 后第 1 次取样, WW 维 持 $80 \%$ 田间持水量, D 和 MT+D 停止供水达到 50\%田间持水量; 17 : 不同处理 $17 \mathrm{~d}$ 后第 2 次取样, $\mathrm{WW}$ 维持 $80 \%$ 田间持水量, D 和 $\mathrm{MT}+\mathrm{D}$ 第 1 次取样结束后维持 $50 \%$ 田间持水量; 24 : 不同处理 $24 \mathrm{~d}$ 后第 3 次取样, WW 维持 $80 \%$ 田间持水量, D 和 MT $+\mathrm{D}$ 第 2 次取样结束后 继续维持 $50 \%$ 田间持水量。标以不同字母的柱值在 $P<0.05$ 水平上差异显著。

A: net photosynthetic rate; B: stomatal conductance; C: transpiration rate; D: intercellular carbon dioxide concentration; E: water use efficiency; F: ribulose-1,5-bisphosphate carboxylase. WW: keeping $80 \%$ of the field water holding capacity, from the beginning of the seed filling stage, and leaf spray with water for $5 \mathrm{~d}$; D: no water supply and maintain $50 \%$ of the field water holding capacity at seed filling stage, and leaf spray with water for $5 \mathrm{~d}$; MT+D: no water supply and maintaining $50 \%$ of the field water holding capacity at seed filling stage, and leaf spray with $100 \mu \mathrm{mol} \mathrm{L}{ }^{-1}$ melatonin plus drought stress for $5 \mathrm{~d}$. 10: the first sampling after $10 \mathrm{~d}$ of different treatments, at that time WW maintained $80 \%$ of field water holding capacity, D and MT + D stopped water supply water to reach $50 \%$ of field water holding capacity; 17 : the second sampling after 17 days of different treatments, at that time WW maintained $80 \%$ of field holding water volume, D and MT+D maintained 50\% field water holding capacity after the first sampling; 24 : the third sampling after 24 days of different treatments, at that time WW maintained $80 \%$ field water holding capacity, D and MT+D maintained $50 \%$ field water holding capacity after the second sampling. Bars superscripted by different letters are significantly different at $P<0.05$. 


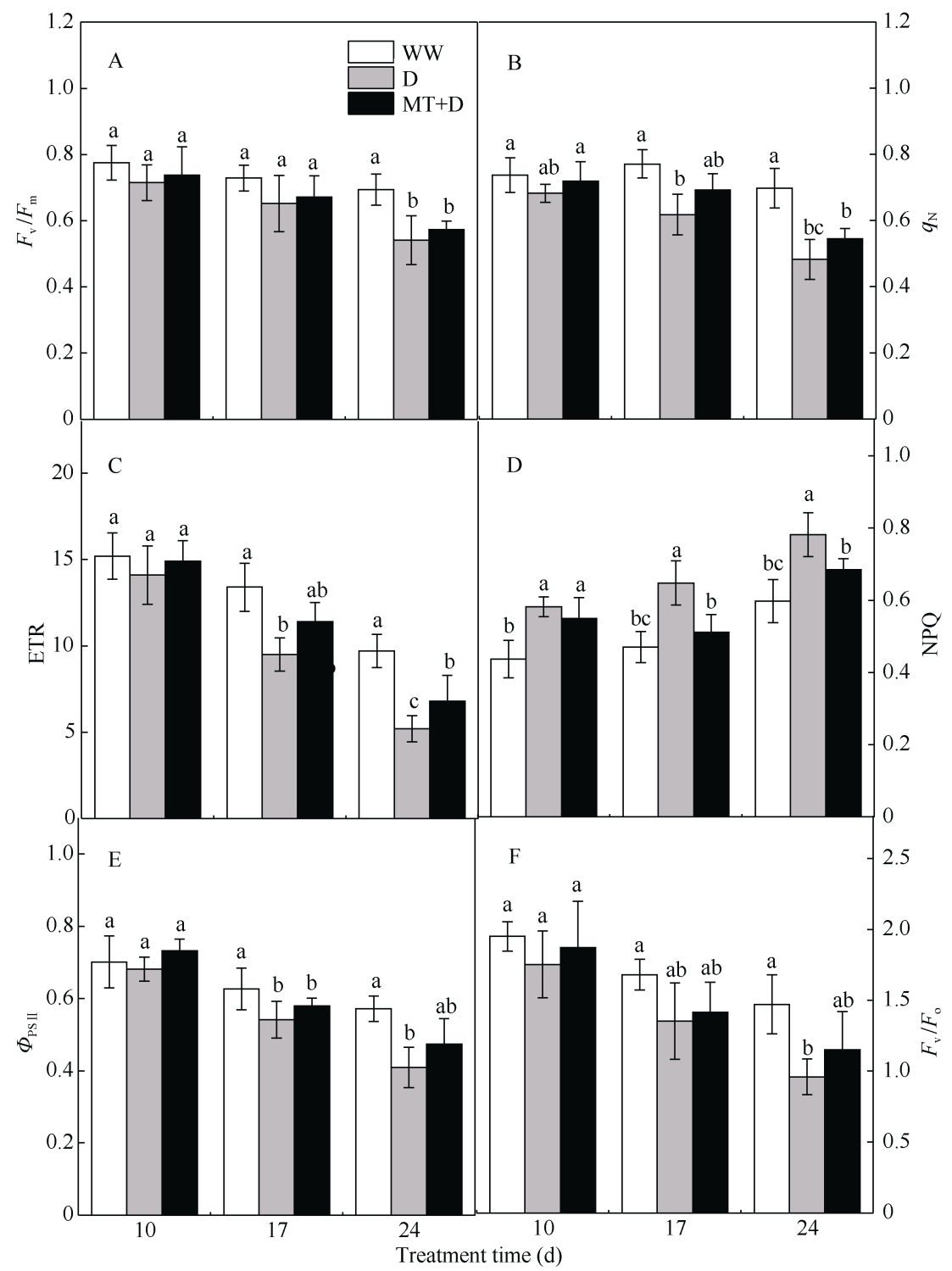

图 2 外源褪黑素对干旱胁迫下大豆鼓粒期叶片叶绿素荧光参数的影响

Fig. 2 Effects of exogenous melatonin on chlorophyll fluorescence parameters of soybean during seed filling stage under drought stress

A：光系统 II 光能转换效率; B：光化学猝灭系数; C：表观电子传递速率; D：非光化学猝灭系数; E：光系统 II 实际光化学效率; F：光系 统 II 实际最大光能转化效率。标以不同字母的柱值在 $P<0.05$ 水平上差异显著。缩写同图 1。

A: photosystem II light energy conversion efficiency; B: photochemical quenching coefficient; C: apparent electron transfer rate; D: non-photochemical quenching coefficient; E: photosystem II actual photochemical efficiency; $\mathrm{F}$ : the actual maximum light energy conversion efficiency of photo system II. Bars superscripted by different letters are significantly different at $P<0.05$. Abbreviations are the same as those given in Fig. 1.

降低趋势; NR (图 4-C)和 GOGAT (图 4-F)活性呈先 上升后下降趋势。与干旱胁迫相比, 裉黑素处理降 低了 $\mathrm{NO}_{3}{ }^{-}$和 $\mathrm{NH}_{4}{ }^{+}$的含量, 提高了 $\mathrm{NR} 、 \mathrm{GS} 、 \mathrm{GOGAT}$ 和 GDH 活性。

\section{5 外源裉黑素对干旱胁迫下大豆抗氧化酶活} 性的影响

与正常供水相比, 干旱胁迫增加了 SOD (图 5-A)、
POD (图 5-B)、CAT (图 5-C)和 APX (图 5-D)活性, 且 随胁迫延长呈现先上升后下降趋势; GR (图 5-E)、 GPX (图 5-F)、MDHAR (图 5-G)和 DHAR 活性(图 5-H)随干旱时间延长呈不断降低趋势。褪黑素处理 可以提高干旱胁迫下 SOD、POD、CAT、APX、GR、 GPX、MDHAR 和 DHAR 的活性, 第 10 天的效果较 第 17 天和第 24 天更好。 


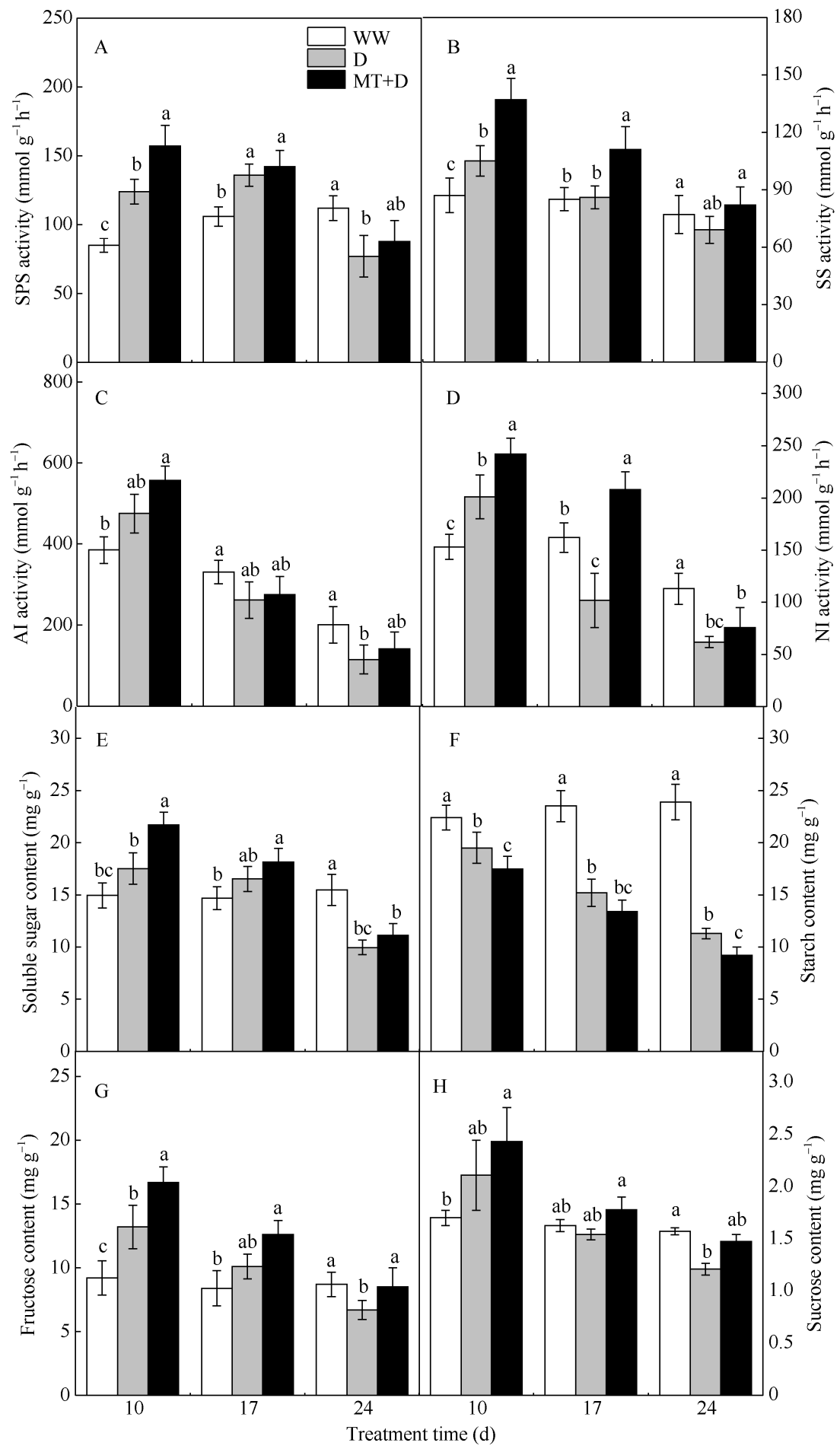

图 3 外源褪黑素对干旱胁迫下大豆鼓粒期叶片碳代谢的影响

Fig. 3 Effects of exogenous melatonin on leaf carbon metabolism in soybean during seed filling stage under drought stress A：蔗糖磷酸合酶; B: 蔗糖合酶; C: 酸性转化酶; D: 中性转化酶; E: 可溶性糖; F: 淀粉; G: 果糖; H: 蔗糖。标以不同字母的柱值在 $P$ $<0.05$ 水平上差异显著。缩写同图 1 。

A: sucrose phosphate synthase; B: sucrose synthase; C: acid invertase; D: neutral invertase; E: soluble sugar; F: starch; G: fructose; H: sucrose. Bars superscripted by different letters are significantly different at $P<0.05$. Abbreviations are the same as those given in Fig. 1 . 


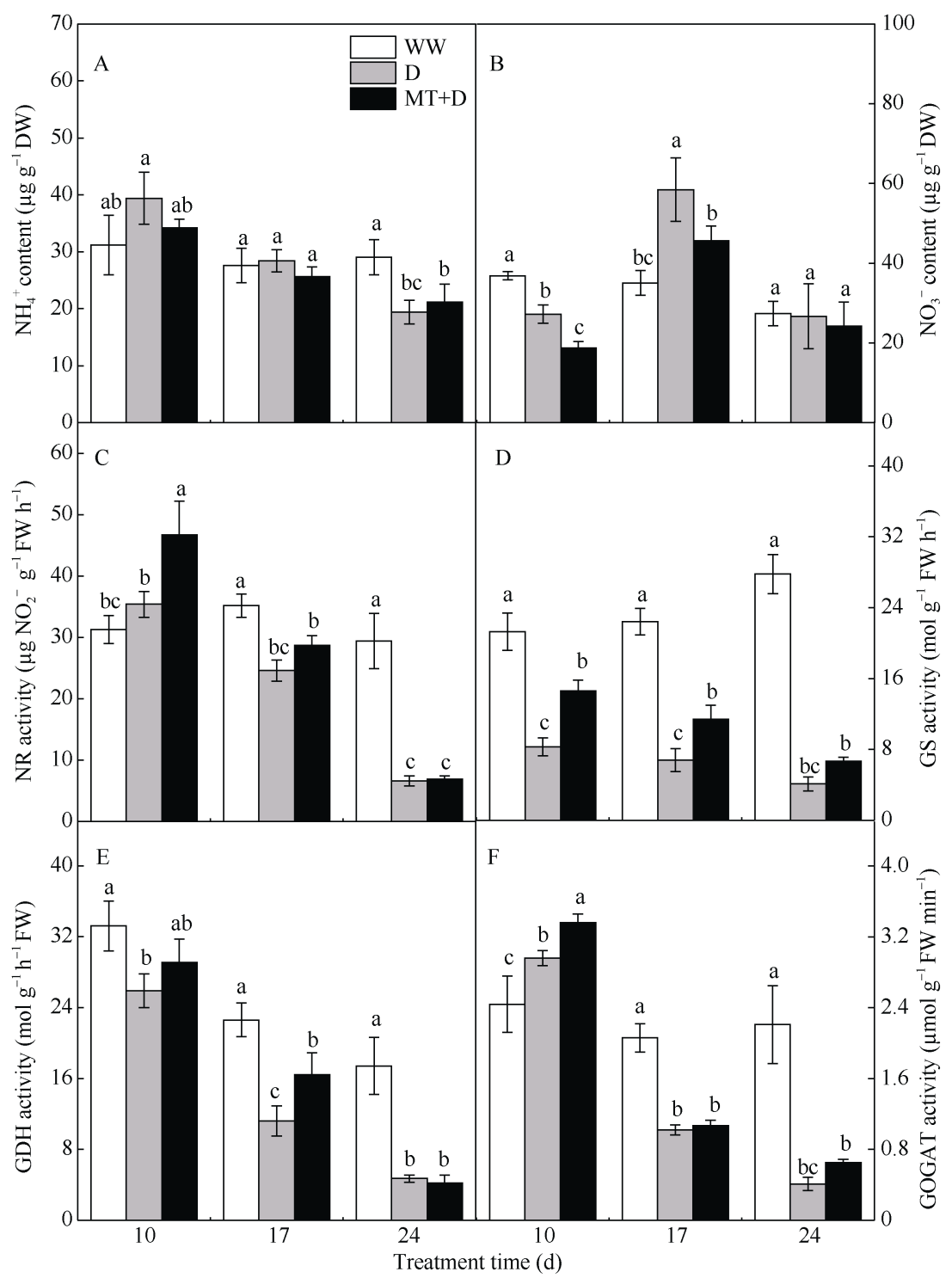

图 4 外源褪黑素对干旱胁迫下大豆鼓粒期叶片氮代谢的影响

Fig. 4 Effects of exogenous melatonin on nitrogen metabolism in soybean during seed filling stage under drought stress

$\mathrm{A}$ : 铵态氮; B: 硝态氮; C: 硝酸还原酶; D: 谷氨酰胺合成酶; $\mathrm{E}$ : 谷氨酸脱氢酶; $\mathrm{F}$ : 谷氨酸合成酶。标以不同字母的柱值在 $P<0.05$ 水 平上差异显著。缩写同图 1 。

A: ammonium nitrogen; B: nitrate nitrogen; C: nitrate reductase; D: glutamine synthetase; E: glutamate dehydrogenase; F: glutamate synthetase. Bars superscripted by different letters are significantly different at $P<0.05$. Abbreviations are the same as those given in Fig. 1 .

\section{6 外源褪黑素对干旱胁迫下大豆抗氧化剂含} 量的影响

与正常供水相比, 干旱胁迫提高了第 10 天和第 17 天 GSH (图 6-A)和 ASA (图 6-B)含量, 降低了第 24 天 GSH 含量, 并低于正常供水, 第 24 天 ASA 含量较第 17 天有所降低但仍高于正常供水。褪黑素处理可以增加干 旱胁迫下 ASA 和 GSH 的含量, 其中 GSH 含量增幅在第 17 天效果更好, 而 ASA 含量增幅在第 10 天效果更好。
2.7 外源褪黑素对干旱胁迫下大豆膜脂过氧化 的影响

与正常供水相比, 干旱胁迫增加了 $\mathrm{O}_{2}^{-}$产生速 率(图 7-A)、 $\mathrm{H}_{2} \mathrm{O}_{2}$ 含量(图 7-B)、MDA 含量(图 7-C) 和 REL (图 7-D), 且随着干旱胁迫的延长呈不断上 升趋势。褪黑素处理可以减轻干旱胁迫下的 $\mathrm{O}_{2}{ }^{-}$产生 速率、 $\mathrm{H}_{2} \mathrm{O}_{2}$ 含量, 以及 MDA 含量和 REL 的上升, 且 第 10 天的效果更好。 


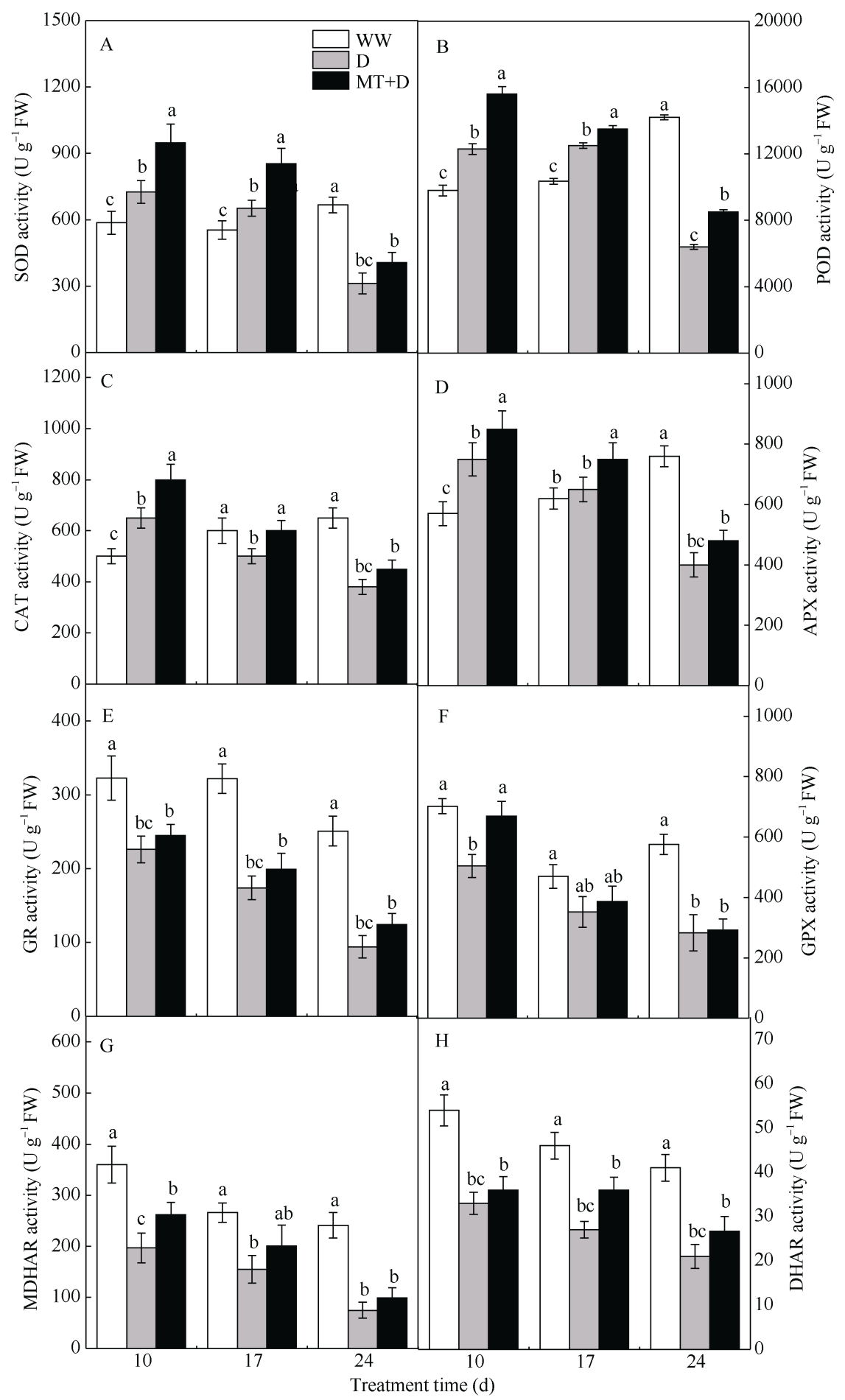

图 5 外源褪黑素对干旱胁迫下大豆鼓粒期叶片抗氧化酶活性的影响

Fig. 5 Effects of exogenous melatonin on antioxidant enzyme activities in leaves of soybean during seed filling stage under drought stress

A：超氧化物歧化酶；B：过氧化物酶; C: 过氧化氢酶; D：抗坏血酸过氧化物酶; E：谷胱甘肽还原酶; F：谷胱甘肽过氧化物酶; G：单 脱氢抗坏血酸还原酶; $\mathrm{H}$ : 脱氢抗坏血酸还原酶。标以不同字母的柱值在 $P<0.05$ 水平上差异显著。缩写同图 1 。

A: superoxide dismutase; B: peroxidase; C: catalase; D: ascorbate peroxidase; E: glutathione reductase; F: glutathione peroxidase; G: monodehydroascorbate reductase; H: hydrogen ascorbate reductase. Bars superscripted by different letters are significantly different at $P<$ 0.05. Abbreviations are the same as those given in Fig. 1. 


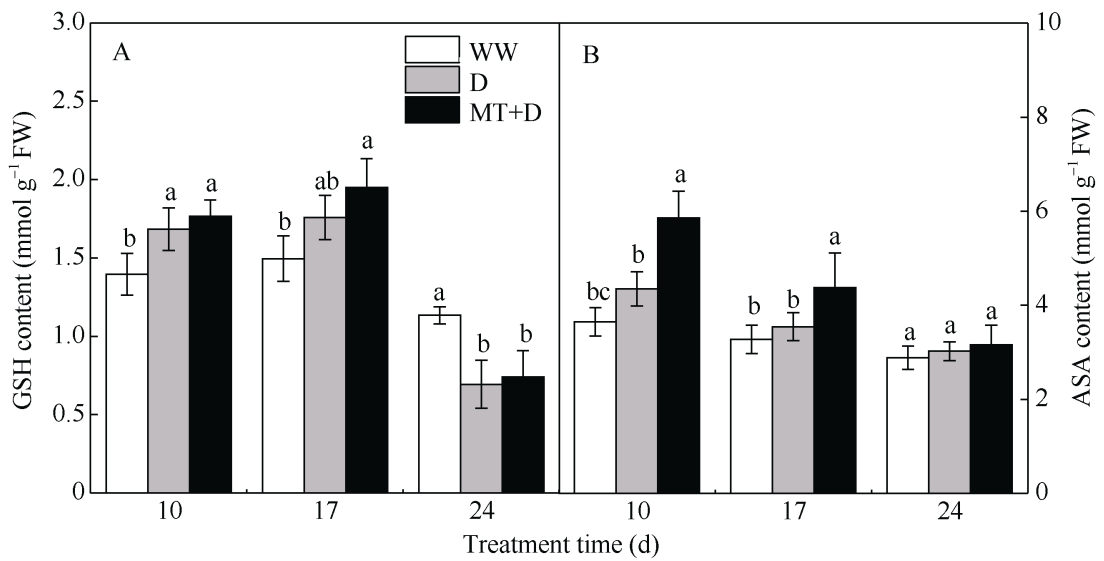

图 6 外源褪黑素对干旱胁迫下大豆鼓粒期叶片抗氧化剂含量的影响

Fig. 6 Effects of exogenous melatonin on antioxidants in leaves of soybean during seed filling stage under drought stress $\mathrm{A}$ : 谷胱甘肽; $\mathrm{B}$ : 抗坏血酸。标以不同字母的柱值在 $P<0.05$ 水平上差异显著。缩写同图 1 。

A: glutathione; B: ascorbic acid. Bars superscripted by different letters are significantly different at $P<0.05$. Abbreviations are the same as those given in Fig. 1.

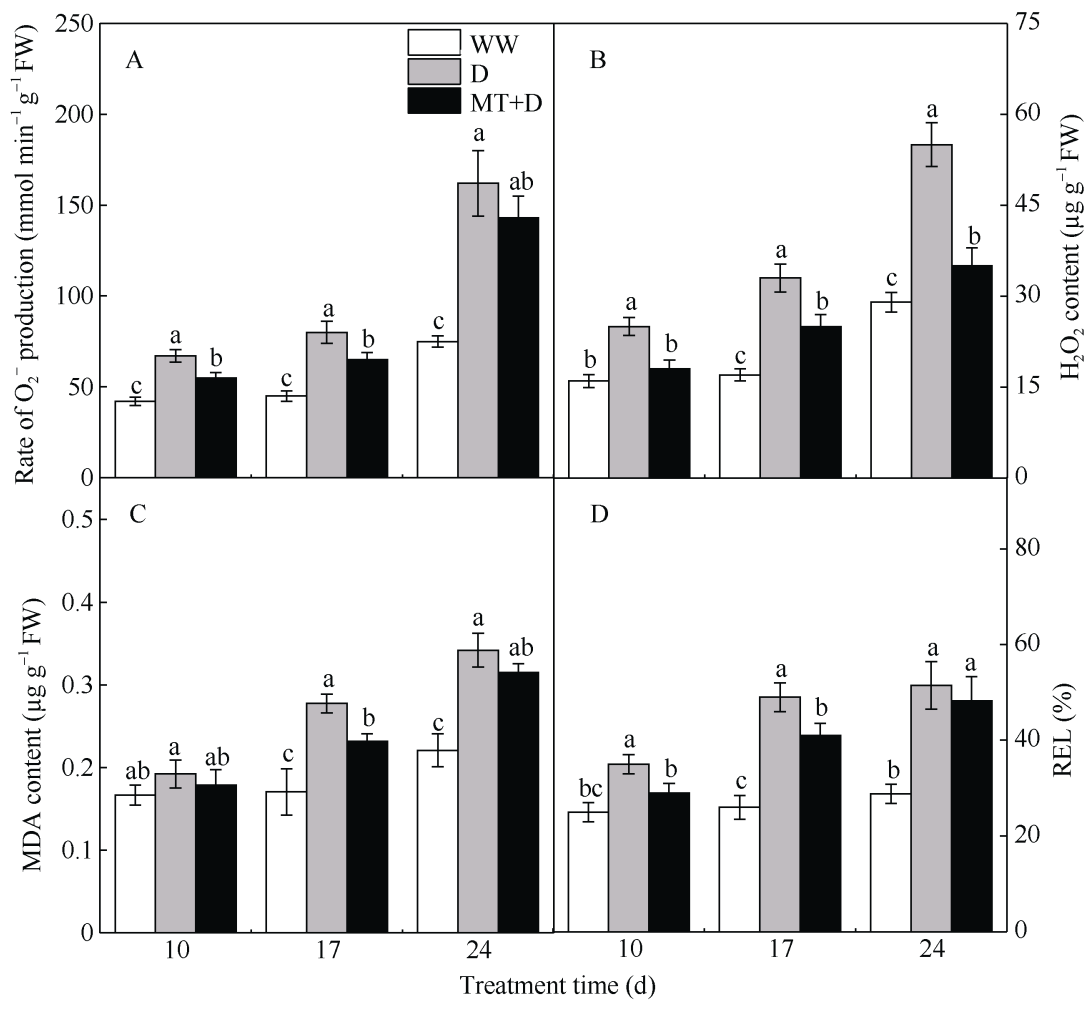

图 7 外源褪黑素对干旱胁迫下大豆鼓粒期叶片膜脂过氧化的影响

Fig. 7 Effects of exogenous melatonin on membrane lipid peroxidation in soybean during seed filling stage under drought stress $\mathrm{A}$ : 超氧阴离子产生速率; $\mathrm{B}$ : 过氧化氢含量; $\mathrm{C}$ : 丙二醛含量; $\mathrm{D}$ : 相对电导率。标以不同字母的柱值在 $P<0.05$ 水平上差异显著。缩写 同图 1。

A: superoxide anion production rate; B: hydrogen peroxide content; C: malondialdehyde content; D: relative conductivity. Bars superscripted by different letters are significantly different at $P<0.05$. Abbreviations are the same as those given in Fig. 1.

\section{8 外源褪黑素对干旱胁迫下大亘产量的影响} 由表 1 可知, 干旱胁迫(D)降低鼓粒期大亘单株 荚数、单株粒数、单株粒重和百粒重。褪黑素处理 可提高干旱胁迫下单株荚数、单株粒数、单株粒重
和百粒重。与干旱胁迫相比，单株荚数、单株粒数、 单株粒重和百粒重 2017 年分别提高了 $1.9 \%$ 、 $0.7 \%$ 、 $13.2 \% 、 18.1 \% ; 2018$ 年分别提高了 $4.0 \% 、 0.9 \%$ 、 $16.2 \% 、 16.4 \%$ 。 
表 1 外源褪黑素对干旱胁迫下鼓粒期大豆产量以及减产率和缓解率的影响

Table 1 Effect of exogenous melatonin on soybean yield and yield reduction rate and remission rate in seed filling stage under drought stress

\begin{tabular}{|c|c|c|c|c|c|c|c|}
\hline $\begin{array}{l}\text { 年份 } \\
\text { Year }\end{array}$ & $\begin{array}{c}\text { 处理 } \\
\text { Treatment }\end{array}$ & $\begin{array}{c}\text { 单株荚数 } \\
\text { Pods per plant }\end{array}$ & $\begin{array}{c}\text { 单株粒数 } \\
\text { Seeds per pod }\end{array}$ & $\begin{array}{c}\text { 单株粒重 } \\
\text { Grain weight } \\
\text { per plant (g) }\end{array}$ & $\begin{array}{c}\text { 百粒重 } \\
\text { Hundred grain } \\
\text { weigh }(\mathrm{g})\end{array}$ & $\begin{array}{c}\text { 减产率 } \\
\text { Yield reduction } \\
\text { rate }(\%)\end{array}$ & $\begin{array}{c}\text { 缓解率 } \\
\text { Remission rate } \\
(\%)\end{array}$ \\
\hline \multirow[t]{3}{*}{2017} & $\mathrm{MT}+\mathrm{D}$ & $24.80 \pm 1.52 \mathrm{a}$ & $46.63 \pm 6.92 \mathrm{a}$ & $9.75 \pm 0.83 \mathrm{~b}$ & $16.55 \pm 2.21 \mathrm{~b}$ & & \\
\hline & $\mathrm{D}$ & $24.32 \pm 2.15 \mathrm{a}$ & $46.27 \pm 4.47 \mathrm{a}$ & $8.61 \pm 1.42 \mathrm{bc}$ & $14.01 \pm 1.19 \mathrm{c}$ & -24.6 & 9.9 \\
\hline & WW & $25.80 \pm 1.40 \mathrm{a}$ & $47.70 \pm 3.40 \mathrm{a}$ & $11.42 \pm 1.89 \mathrm{a}$ & $20.78 \pm 0.83 \mathrm{a}$ & & \\
\hline \multirow[t]{3}{*}{2018} & $\mathrm{MT}+\mathrm{D}$ & $22.08 \pm 0.64 \mathrm{ab}$ & $42.53 \pm 1.90 \mathrm{ab}$ & $7.01 \pm 0.72 \mathrm{c}$ & $16.11 \pm 1.24 \mathrm{~b}$ & & \\
\hline & $\mathrm{D}$ & $21.23 \pm 0.75 \mathrm{ab}$ & $42.13 \pm 1.98 \mathrm{ab}$ & $6.03 \pm 0.43 \mathrm{~cd}$ & $13.76 \pm 0.91 \mathrm{c}$ & -36.3 & 10.3 \\
\hline & WW & $22.54 \pm 0.14 \mathrm{ab}$ & $42.67 \pm 2.63 \mathrm{ab}$ & $9.47 \pm 0.27 \mathrm{~b}$ & $21.52 \pm 0.91 \mathrm{a}$ & & \\
\hline
\end{tabular}

同栏内标以不同字母的值在 $P<0.05$ 水平上差异显著。减产率 $=(\mathrm{D}-\mathrm{WW}) / \mathrm{WW} \times 100 \%$; 缓解率 $=[(\mathrm{WW}-\mathrm{D}) / \mathrm{WW}-(\mathrm{WW}-\mathrm{MT}) /$ $\mathrm{WW}] \times 100 \%$, 以单株粒重计算。缩写同图 1 。

The values with in the same column followed by different letters are significantly different at $P<0.05$. Yield reduction rate $=(\mathrm{D}-$ $\mathrm{WW}) / \mathrm{WW} \times 100 \%$; Remission rate $=[(\mathrm{WW}-\mathrm{D}) / \mathrm{W}-(\mathrm{WW}-\mathrm{MT}) / \mathrm{W}] \times 100 \%$, calculated with grain weight per plant. Abbreviations are the same as those given in Fig. 1.

\section{3 讨论}

干旱胁迫降低植株叶绿体光能复合体电子传递 能力和 $\mathrm{CO}_{2}$ 固定效率, NADP ${ }^{+}$供应减少, 导致在 PSI 中生产 $\mathrm{O}_{2}{ }^{-}$, 又经 PSII 生产 $\mathrm{H}_{2} \mathrm{O}_{2}{ }^{\left[{ }^{[3]}\right.}$ 。植物会激发酶 促系统和非酶促系统来清除过量 ROS, 包括抗氧化 酶和抗氧化剂 ${ }^{[35]}$ 。本试验研究发现, 干旱胁迫第 10 天会显著提高 SOD、POD、CAT 和 APX 活性, 干旱 胁迫至第 24 天, 抗氧化酶活性低于对照。Huang 等 ${ }^{[15]}$ 研究表明玉米幼苗在干旱胁迫下外源褪黑素提升抗 氧化酶活性。本研究同样发现褪黑素处理较干旱胁 迫可提高抗氧化酶活性, 在处理第 10 天和 17 天提 高幅度较大, 在第 24 天增幅较小, 这可能与胁迫时 间延长或褪黑素生理功能下降有关。褪黑素并不具 有直接清除 ROS 的功能 ${ }^{[36]}$, 褪黑素对氧化还原稳态 的调节是由于其诱导抗氧化酶活性提高。SOD 作为 $\mathrm{ROS}$ 清除的第一道防线，可将 $\mathrm{O}_{2}{ }^{-}$歧化为 $\mathrm{O}_{2}$ 和 $\mathrm{H}_{2} \mathrm{O}_{2}$, CAT 能清除过氧化物酶体中 $\mathrm{H}_{2} \mathrm{O}_{2}{ }^{[37]}$ 。在线粒体过氧 化物酶中存在 ASA-GSH 循环酶系统, 包括 MDHAR、DHAR、GR 和 GPX 共同参与 $\mathrm{H}_{2} \mathrm{O}_{2}$ 的清 除过程, 并参与 ASA 和 GSH 循环再生过程 ${ }^{[19]}$ 。据 研究表明干旱胁迫提高玉米叶片 MDHAR、DHAR、 GR 和 GPX 活性 ${ }^{[38]}$ 。本试验表明, 干旱胁迫会降低 MDHAR、DHAR、GR 和 GPX 活性, 鼓粒期作为最 后一个时期自身防御系统较弱, 对胁迫更敏感。褪 黑素能促进西瓜 ASA-GSH 循环中 APX 和 MDHAR 活性, 增加 ASA 和 GSH 含量, 减轻 ROS 积累和随 后的氧化应激 ${ }^{[27]}$ 。本研究表明褪黑素处理显著提高 了干旱胁迫下 MDHAR、DHAR、GR 和 GPX活性, 平
衡氧化还原稳态以及促进 GSH 和 ASA 含量的再生 循环, 这有助于清除过量 ROS、APX以ASA 为底物, 在 ASA-GSH 循环中将 $\mathrm{H}_{2} \mathrm{O}_{2}$ 还原为 $\mathrm{H}_{2} \mathrm{O}$, 产生 MDHA 后再产生 MDHAR; GSH 和 ASA 可直接与 $\mathrm{HO}_{2}{ }^{-} 、 \mathrm{O}_{2}{ }^{-}$和 ${ }^{1} \mathrm{O}_{2}$ 等 $\mathrm{ROS}$ 反应，将有机自由基 $\mathrm{R}$ 还原

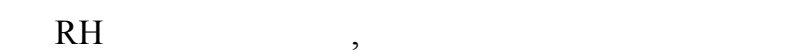
的整个抗氧化系统来改善细胞氧化还原稳态，从而 保护细胞免受干旱胁迫诱导的氧化应激 ${ }^{[39]}$ 。

ROS 的产生与清除平衡机制是其含量的基础, ROS 作为信使诱导抗氧化酶基因表达, 但过量的 ROS 促进抗氧化酶活性提升并不足以清除它们。 ROS 还会转移到类囊体和细胞膜, 引发膜脂过氧化, 从而破坏膜结构 ${ }^{[40]}$ 。干旱胁迫程度加深会持续提高 ROS 和 MDA 含量积累 ${ }^{[41]}$, 本试验表明, 随着干旱 胁迫时间延长, $\mathrm{H}_{2} \mathrm{O}_{2}$ 含量、 $\mathrm{O}_{2}{ }^{-}$产生速率、MDA 含量 和相对电导率呈现不断上升, 说明干旱胁迫导致 ROS 过度积累, 细胞膜受到损伤, 电解质外渗增加。 褪黑素处理缓解了干旱胁迫下 $\mathrm{H}_{2} \mathrm{O}_{2}$ 和 MDA 的积累, 以及相对电导率的下降, 说明褪黑素调节膜脂过氧 化渗透平衡, 保护细胞膜系统完整性, 主要原因与 褪黑素可以增强大豆叶片抗氧化酶活性有关, 也与 褪黑素具有抑制膜质过氧化的级联反应有关 ${ }^{[42]}$, 这 有助于清除部分过量 ROS 积累, 缓解细胞膜损伤、 光合色素降解、蛋白质大分子降解等。

光合作用是作物生长发育过程中重要的能量转 化代谢系统, 提高光合能力有助于为植物生长发 育、籽粒生物量积累奠定基础, 是作物产量形成的 物质基础 ${ }^{[43]}$ 。在本研究中, 干旱胁迫条件下, 植物通 过关闭气孔以减少水分流失, $G_{\mathrm{s}}$ 和 $T_{\mathrm{r}}$ 下降, 气孔关 
闭导致吸收 $\mathrm{CO}_{2}$ 不足而抑制光合作用 ${ }^{[44]}$ ，长期干旱 胁迫提高 $C_{\mathrm{i}}$, 可能与非气孔限制有关, 说明干旱胁 迫已损伤光合系统和叶组织, 空气中 $\mathrm{CO}_{2}$ 直接通过 叶片缝隙进入叶片内部, 抑制了对光能的吸收, 降 低了光合作用正常运行和碳同化过程, 阻碍了光反 应形态的同化力还原熫糖的能力 ${ }^{[45]}$ 。本试验表明褪 黑素处理可以缓解干旱胁迫下 $P_{\mathrm{n}} 、 G_{\mathrm{s}} 、 T_{\mathrm{r}}$ 和叶绿素 含量的下降, 在第 24 天降低了 $C_{\mathrm{i}}$ 说明裉黑素处理 $P_{\mathrm{n}}$ 下降是气孔限制因素, 缓解了干旱胁迫对光合系 统的伤害, 这与之前的研究结果一致 ${ }^{[15,20,41,46-47]}$ 。褪 黑素处理缓解了干旱胁迫对光能吸收利用抑制, 提 高碳同化产物蔗糖含量和叶片对籽粒运输能力, 有 助于生长发育和产量提升。

PSII 的部分激发能通过电子传递为 $\mathrm{CO}_{2}$ 固定提 供能量, 干旱胁迫降低了光合速率, 导致吸收的光 能过剩, 不能散失的光能为 ROS 积累提供能量, 对 光合系统产生损伤或者以热的形式散发 ${ }^{[48]}$ 。本试验 表明, 干旱胁迫降低 $F_{\mathrm{v}} / F_{\mathrm{m}} 、 F_{\mathrm{v}} / F_{\mathrm{o}} 、 \Phi_{\mathrm{PSII}} 、 \mathrm{ETR}$ 和 $q_{\mathrm{N}}$, 提高 NPQ, 说明干旱胁迫对光合系统产生损伤, 降低了光合转化效率。Ye 等 ${ }^{[46]}$ 研究发现外源裉黑素 能提高干旱胁迫下玉米幼苗叶绿素苂光。本试验表 明, 褪黑素处理可以提高干旱胁迫下大豆叶片 $F_{\mathrm{v}} / F_{\mathrm{m}} 、 F_{\mathrm{v}} / F_{\mathrm{o}} 、 \Phi_{\mathrm{PSII}} 、 \mathrm{ETR}$ 和 $q_{\mathrm{N}}$, 降低 NPQ; 说明褪 黑素处理能缓解干旱对光合系统的损伤, 提高光能 利用效率和电子传递能力, 并对 ROS 积累有一定抑 制作用。

碳代谢与植株生长和产量密切相关, 在植株遭 受干旱胁迫时, 叶片光合速率下降, 光合同化物形 成量减少, 糖类物质含量增加, 光呼吸活性提高, 以蔗糖为主要运输形式的光合同化物加速向根系转 运 ${ }^{[49]}$ 。Wei 等 ${ }^{[4]}$ 研究表明, 褪黑素能上调盐胁迫下 大豆碳代谢中丙酮酸转运能力和葡萄糖和果糖间转 化水平。本试验表明, 褪黑素能提高干旱胁迫下蔗 糖和果糖含量, SS、SPS、NI 和 AI 活性, 降低淀粉 含量, SPS 和 SS 能够催化合成蔗糖, NI 和 AI 促进蔗 糖和淀粉向己糖方向转化, 导致果糖在叶片中积累 以及在碳水化合物之间转化 ${ }^{[45]}$, 大量积累的己糖 不仅维持细胞膨压稳定, 又反馈抑制光合作用, 淀 粉与蔗糖存在相互转换功能, 淀粉含量降低可能与 褪黑素降低了干旱胁迫下磷酸丙酮转化淀粉能力 或者提高了大豆叶片内淀粉分解酶活性有关。提高 糖的积累合成和转化能力, 能提高渗透调节平衡以 维持正常的细胞势, 还能为同化物运输提供能量, 为氮代谢提供碳源和能量, 促进蛋白质和氨基酸的
合成 ${ }^{[50]}$ 。

氮代谢对作物的生长发育、产量形成具有重要 的生理作用，氮代谢为碳骨架提供蛋白 ${ }^{[51]}$ 。干旱胁 迫降低氮代谢相关酶的活性, 增加氮分解代谢酶活 性 ${ }^{[52]}$ 。本研究发现, 干旱胁迫会降低氮代谢相关酶 活性从而降低 $\mathrm{NO}_{3}{ }^{-}$和 $\mathrm{NH}_{4}{ }^{+}$同化能力, 因 $\mathrm{GDH}$ 与 $\alpha-$ 酮戊二酸同化 $\mathrm{NH}_{4}$ 与 $\mathrm{NH}_{4}{ }^{+}$合成谷氨酸, 再通过 $\mathrm{GS}$ 和 GOGAT 合成各种氨基酸, 因此抑制蛋白质、叶绿 素和核酸等多种含氮化合物的合成。Zhang 等 ${ }^{[53]}$ 研 究表明, 外源褪黑素可提升 $\mathrm{NaHCO}_{3}$ 胁迫下下黄瓜 幼苗叶片的氮代谢水平。本研究表明, 外源裉黑素 能提高干旱胁迫下大豆叶片氮代谢相关酶的活性, 这有助于促进氮代谢过程中同化能力, 缓解因 $\mathrm{NO}_{3}{ }^{-}$ 和 $\mathrm{NH}_{4}{ }^{+}$的积累形成氨毒, 对维持大豆正常生长、叶 绿素合成等具有促进作用。

干旱胁迫会抑制植物生长和发育进程、营养物 质的合成与转运、光合作用以及基因和蛋白水平表 达, 改变形态结构、相关酶活性和水分分配方向 ${ }^{[39]}$ 。 而产量与光合作用直接相关, 抗逆性可维护细胞膜 结构，氧化还原稳态，以及保护碳氮代谢的同化物 吸收转运, 保护蛋白质分子结构合成叶绿体等细胞 器和蔗糖-淀粉代谢等, 从而维护光合作用正常运 行。本研究发现, 干旱胁迫通过降低百粒重来降低 产量, 说明干旱胁迫抑制了子粒的生长, 或许与减 缓光合同化物向子粒运输有一定关系。褪黑素能缓 解干旱胁迫对百粒重的抑制和叶片的结构损伤, 促 进碳氮同化能力和光合能力, 这可能会加速向子粒 运输光合产物促进子粒发育进而提高产量。

\section{4 结论}

外源褪黑素提高了干旱胁迫下大豆叶片中抗氧 化酶活性和抗氧剂含量, 从而减少 ROS 积累, 降低 了膜脂过氧化程度, 保护 PSII 系统提高电子传递和 利用效率，提升光合能力和碳氮代谢同化能力。此 外, 与正常供水相比, 裉黑素减少了干旱胁迫下产 量损失, 2017 年干旱胁迫降低了 $24.6 \%$ 产量, 褪黑素 处理缓解因干旱胁迫造成 $9.9 \%$ 的产量损失; 2018 年 干旱胁迫降低了 $36.3 \%$ 产量, 褪黑素处理缓解了因 干旱造成的 $10.3 \%$ 的产量损失。

\section{References}

[1] 李琬. 干旱对大豆根系生育的影响及灌溉缓解效应研究进展. 草业学报, 2019, 28(4): 192-202.

Li W. Research progress in understanding the effects of drought on growth of the soybean root system and the efficiency of 
irrigation. Acta Pratac Sin, 2019, 28(4): 192-202 (in Chinese with English abstract).

[2] Meckel L, Egli D B, Phillips R E, Radcliffe D, Leggett J E. Effect of moisture stress on seed growth in soybeans. Agron J, 1984, 76: 647-650.

[3] Westgate M E, Peterson C M. Flower and pod development in water deficient soybean. $J$ Exp Bot, 1993, 258: 109-117.

[4] Getachew M. Influence of soil water deficit and phosphorus application on phosphorus uptake and yield of soybean (Glycine $\max$ L.) at Dejen, North-West Ethiopia. Am J Plant Sci, 2014, 5: 1889-1906.

[5] Kangasjärvi S, Neukermans J, Li S, Aro E M, Noctor G. Photosynthesis, photorespiration, and light signalling in defence responses. J Exp Bot, 2012, 63: 1619-1636.

[6] Tikkanen M, Grieco M, Aro E M. Novel insights into plant light-harvesting complex II phosphorylation and 'state transitions'. Trends Plant Sci, 2011, 16: 126-131.

[7] Manavalan L P, Guttikonda S K, Phan Tran L S, Nguyen H T. Physiological and molecular approaches to improve drought resistance in soybean. Plant Cell Physiol, 2009, 50: 1260-1276.

[8] 邹京南, 曹亮, 王梦雪, 金喜军, 任春元, 王明瑶, 于奇, 张玉 先. 外源褪黑素对干旱胁迫下大豆结荚期光合及生理的影响. 生态学杂志, 2019, 38: 2709-2718.

Zou J N, Cao L, Wang M X, Jin X J, Ren C Y, Wang M Y, Yu Q, Zhang Y X. Effects of exogenous melatonin on photosynthesis and physiology of soybean seedlings under drought stress. Chin J Ecol, 2019, 38: 2709-2718 (in Chinese with English abstract).

[9] 丁秀文, 张国良, 戴其根, 朱青. 1,2,4-三氯苯胁迫对水稻分蒒采 盛期植株生长和生理特性的影响. 作物学报, 2014, 40: 487-496.

Ding $\mathrm{X}$ W, Zhang G L, Dai Q G, Zhu Q. Effects of 1,2,4-trichlorobenzene on growth and physiological characteristics of rice at maximum tillering stage. Acta Agron Sin, 2014, 40: 487-496 (in Chinese with English abstract).

[10] 马晓寒, 张杰, 张环纬, 陈彪, 温心怡, 许自成. 通过外源 MeJA 抑制 $\mathrm{H}_{2} \mathrm{O}_{2}$ 积累提高烟草的耐冷性. 作物学报, 2019, 45: 411-418.

Ma X H, Zhang J, Zhang H W, Chen B, Wen X Y, Xu Z C. Exogenous MeJA improves cold tolerance of tobacco by inhibiting $\mathrm{H}_{2} \mathrm{O}_{2}$ accumulation. Acta Agron Sin, 2019, 45: 411-418 (in Chinese with English abstract).

[11] Gil-Quintana E, Larrainzar E, Seminario A, Díaz-Leal J L, Alamillo J M, Pineda M, Arrese-Igor C, Wienkoop S, González E M. Local inhibition of nitrogen fixation and nodule metabolism in drought-stressed soybean. J Exp Bot, 2013, 64: 2171-2182.

[12] Larrainzar E, Molenaar J A, Wienkoop S, Gil-Quintana E, Alibert B, Limami A M, Arrese-Igor C, Gonzalez E M. Drought stress provokes the down-regulation of methionine and ethylene biosynthesis pathways in Medicago truncatula roots and nodules. Plant Cell Environ, 2014, 37: 2051-2063.

[13] Peleg Z, Blumwald E. Hormone balance and abiotic stress tolerance in crop plants. Curr Opin Plant Biol, 2011, 14: 290-295.

[14] Tan D X, Hardeland R, Manchester L C, Korkmaz A, Ma S, Rosales-Corral S, Reiter R J. Functional roles of melatonin in plants, and perspectives in nutritional and agricultural science. $J$ Exp Bot, 2012, 63: 577-597.
[15] Huang B, Chen Y E, Zhao Y Q, Ding C B, Liao J Q, Hu C, Zhou L J, Zhang Z W, Yuan S, Yuan M. Exogenous melatonin alleviates oxidative damages and protects photosystem II in maize seedlings under drought stress. Front Plant Sci, 2019, 10: 677.

[16] 杨小龙, 须晖, 李天来, 王莈. 外源褪黑素对干旱胁迫下番茄 叶片光合作用的影响. 中国农业科学, 2017, 50: 3186-3195.

Yang X L, Xu H, Li T L, Wang R. Effects of exogenous melatonin on photosynthesis of tomato leaves under drought stress. Sci Agric Sin, 2017, 50: 3186-3195 (in Chinese with English abstract).

[17] Cui G, Sun F, Gao X, Xie K, Zhang C, Liu S, Xi Y. Proteomic analysis of melatonin-mediated osmotic tolerance by improving energy metabolism and autophagy in wheat (Triticum aestivum L.). Planta, 2018, 248: 69-87.

[18] Cui G, Zhao X, Liu S, Sun F, Zhang C, Xi Y. Beneficial effects of melatonin in overcoming drought stress in wheat seedlings. Plant Physiol Biochem, 2017, 118: 138-149.

[19] Liu J, Zhang R, Sun Y, Liu Z, Jin W, Sun Y. The beneficial effects of exogenous melatonin on tomato fruit properties. Sci Hortic, 2016, 207: 14-20.

[20] Zou J N, Jin X J, Zhang Y X, Ren C Y, Zhang M C, Wang M X. Effects of melatonin on photosynthesis and soybean seed growth during grain filling under drought stress. Photosynthetica, 2019, 57: 512-520.

[21] Parry M A J, Andralojc P J, Parmar S, Keys A J, Habash D, Paul M J, Alred R, Quick W P, Servaites J C. Regulation of Rubisco by inhibitors in the light. Plant Cell Environ, 1997, 20: 528-534.

[22] Kumar G M, Knowles N R. Changes in lipid peroxidation and lipolytic and free-radical scavenging enzyme activities during aging and sprouting of potato (Solanum tuberosum) seed-tubers. Plant Physiol, 1993, 102: 115-124.

[23] Su G, An Z, Zhang W, Liu Y. Light promotes the synthesis of lignin through the production of $\mathrm{H}_{2} \mathrm{O}_{2}$ mediated by diamine oxidases in soybean hypocotyls. J Plant Physiol, 2005, 162: 1297-1303.

[24] Ke D, Sun G, Wang Z. Effects of superoxide radicals on ACC synthase activity in chilling-stressed etiolated mungbean seedlings. Plant Growth Regul, 2007, 51: 83-91.

[25] Shan C, Liang Z. Jasmonic acid regulates ascorbate and glutathione metabolism in Agropyron cristatum leaves under water stress. Plant Sci, 2010, 178: 130-139.

[26] Loggini B, Scartazza A, Brugnoli E, Navari-Izzo F. Antioxidative defense system, pigment composition, and photosynthetic efficiency in two wheat cultivars subjected to drought. Plant Physiol, 1999, 119: 1091-1100.

[27] Li H, Chang J, Chen H, Wang Z, Gu X, Wei C, Zhang Y, Ma J, Yang J, Zhang X. Exogenous melatonin confers salt stress tolerance to watermelon by improving photosynthesis and redox homeostasis. Front Plant Sci, 2017, 8: 295.

[28] 徐龙光. 黄帝手植柏的组织培养和硝酸还原酶活性测定. 西 北农林科技大学硕士学位论文, 陕西杨凌, 2014.

Xu L G. Tissue Culture and Nitrate Reductase Activity Determination of $P$. sinensis. MS Thesis of Northwest A\&F University, Yangling, Shaanxi, China, 2014 (in Chinese with English abstract).

[29] 屈春媛, 张玉先, 金喜军, 任春元, 张明聪, 王孟雪, 王彦宏, 李菁华, 郑浩宇, 邹京南. 干旱胁迫下外源 $\mathrm{ABA}$ 对鼓粒期大 
豆产量及氮代谢关键酶活性的影响. 中国农学通报, 2017, 33(34): 26-31.

Qu C Y, Zhang Y X, Jin X J, Ren C Y, Zhang M C, Wang M X, Wang Y H, Li J H, Zheng H Y, Zou J N. Effect of exogenous ABA on yield and key enzyme activities of nitrogen metabolism of soybean under drought stress. Chin Agric Bull, 2017, 33(34): 26-31 (in Chinese with English abstract).

[30] Oliveira H C, Freschi L, Sodek L. Nitrogen metabolism and translocation in soybean plants subjected to root oxygen deficiency. Plant Physiol Biochem, 2013, 66: 141-149.

[31] 张志良. 植物生理学实验指导(第 5 版). 北京: 高等教育出版 社. 2016. pp 127-159.

Zhang Z L. Experimental Guidance on Plant Physiology, 5th edn. Beijing: Higher Education Publishers, 2016. pp 127-159 (in Chinese).

[32] Chopra J, Kaur N, Gupta A K. Ontogenic changes in enzymes of carbon metabolism in relation to carbohydrate status in developing mungbean reproductive structures. Phytochemistry, 2000, 53: $539-548$

[33] Tsai C Y, Salamini F, Nelson O E. Enzymes of carbohydrate metabolism in the developing endosperm of maize. Plant Physiol, 1970, 46: 299-306.

[34] Nishiyama Y, Murata N. Revised scheme for the mechanism of photoinhibition and its application to enhance the abiotic stress tolerance of the photosynthetic machinery. Appl Microbiol Biotechnol, 2014, 98: 8777-8796.

[35] 李瑞姣, 陈献志, 岳春雷, 李贺鹏, 王珺, 郭亮, 杨乐. 干旱胁 迫对日本荚蒾幼苗光合生理特性的影响. 生态学报, 2018, 38: 2041-2047.

Li R J, Chen X Z, Yue C L, Li H P, Wang J, Guo L, Yang L. Effects of drought stress on the photosynthetic characteristics of Viburnum japonicum seedlings. Acta Ecol Sin, 2018, 38: 2041-2047 (in Chinese with English abstract).

[36] Bonnefont-Rousselot D, Collin F, Jore D, Gardès-Albert M. Reaction mechanism of melatonin oxidation by reactive oxygen species in vitro. J Pineal Res, 2011, 50: 328-335.

[37] Davey M W, Montagu M V, Inzé D, Sanmartin M, Kanellis A, Smirnoff N, Benzie I J J, Strain J J, Favell D, Fletcher J. Plant 1-ascorbic acid: chemistry, function, metabolism, bioavailability and effects of processing. J Sci Food Agric, 2000, 80: 825-860.

[38] Anjum S A, Ashraf U, Tanveer M, Khan I, Hussain S, Shahzad B, Zohaib A, Abbas F, Saleem M F, Ali I, Wang L C. Drought induced changes in growth, osmolyte accumulation and antioxidant metabolism of three maize hybrids. Front Plant Sci, 2017, 8: 69 .

[39] 王福祥, 肖开转, 姜身飞, 曲梦宇, 连玲, 何炜, 陈丽萍, 谢华 安, 张建福. 干旱胁迫下植物体内活性氧的作用机制. 科学通 报, 2019, 64: 1765-1779.

Wang F X, Xiao K Z, Jiang S F, Qu M Y, Lian L, He W, Chen L P, Xie H A, Zhang J F. Mechanisms of reactive oxygen species in plants under drought stress. Chin Sci Bull, 2019, 64: 1765-1779 (in Chinese with English abstract).

[40] Sharma P, Jha A B, Dubey R S, Pessarakli M. Reactive oxygen species, oxidative damage, and antioxidative defense mechanism in plants under stressful conditions. $J$ Bot, 2012, 10: 1-26.

[41] Liu J, Wang W, Wang L, Sun Y. Exogenous melatonin improves seedling health index and drought tolerance in tomato. Plant Growth Regul, 2015, 77: 317-326.

[42] López-Burillo S, Tan D X, Rodriguez-Gallego V, Manchester L C, Mayo J C, Sainz R M, Reiter R J. Melatonin and its derivatives cyclic 3-hydroxymelatonin, $N^{1}$-acetyl- $N^{2}$-formyl-5-methoxykynuramine and 6-methoxymelatonin reduce oxidative DNA damage induced by Fenton reagents. J Pineal Res, 2003, 34: 178-184.

[43] 李建明, 潘铜华, 王玲慧, 杜清洁, 常毅博, 张大龙, 刘媛. 水 肥耦合对番茄光合、产量及水分利用效率的影响. 农业工程学 报, 2014, 30(10): 82-90.

Li J M, Pan T H, Wang L H, Du Q J, Chang Y B, Zhang D L, Liu Y. Effects of water-fertilizer coupling on tomato photosynthesis, yield and water use efficiency. Trans CSAE, 2014, 30(10): 82-90 (in Chinese with English abstract).

[44] Farooq M, Wahid A, Kobayashi N, Fujita D, Basra S M A. Plant drought stress: effects, mechanisms and management. Agron Sustain Dev, 2009, 29: 153-188.

[45] 邢兴华. $\alpha$-萗乙酸缓解大豆花期逐渐干旱胁迫的生理机制. 南 京农业大学博士学位论文, 江苏南京, 2014.

Xing X H. The Physiological Mechanism of $\alpha$-naphthylacetic Acid to Alleviate the Gradual Drought Stress in Soybean Flowering Stage. PhD Dissertation of Nanjing Agricultural University, Nanjing, Jiangsu, China, 2014 (in Chinese with English abstract).

[46] Ye J, Wang S, Deng X, Yin L, Xiong B, Wang X. Melatonin increased maize (Zea mays L.) seedling drought tolerance by alleviating drought-induced photosynthetic inhibition and oxidative damage. Acta Physiol Plant, 2016, 38: 48.

[47] Wei W, Li Q T, Chu Y N, Reiter R J, Yu X M, Zhu D H, Zhang W K, Ma B, Lin Q, Zhang J S, Chen S Y. Melatonin enhances plant growth and abiotic stress tolerance in soybean plants. $J$ Exp Bot, 2014, 66: 695-707.

[48] 张兴华, 高杰, 杜伟莉, 张仁和, 薛吉全. 干旱胁迫对玉米品 种苗期叶片光合特性的影响. 作物学报, 2015, 41: 154-159.

Zhang X H, Gao J, Du W L, Zhang R H, Xue J Q. Effects of drought stress on photosynthetic characteristics of maize hybrids at seedling stage. Acta Agron Sin, 2015, 41: 154-159 (in Chinese with English abstract).

[49] 邢兴华, 徐泽俊, 齐玉军, 王晓军, 孙东雷, 市能飞, 王幸. 外 源 $\alpha$-萗乙酸对花期干旱大豆碳代谢的影响. 应用生态学报, 2018, 29: 1215-1224.

Xing X H, Xu Z J, Qi Y J, Wang X J, Sun D L, Bian N F, Wang X. Effect of exogenous $\alpha$-naphthaleneacetic acid on carbon metabolism of soybean under drought stress at flowering stage. Chin J Appl Ecol, 2018, 29: 1215-1224 (in Chinese with English abstract).

[50] Commichau F M, Forchhammer K, Stülke J. Regulatory links between carbon and nitrogen metabolism. Curr Opin Microbiol, 2006, 9: 167-172.

[51] 任胜茂, 邓榆川, 文凤君, 刘明洁, 袁小琴, Sajad H, 蒲全明, 刘卫国, 杨文钰. 套作对大豆苗期碳氮物质代谢的影响及其 与抗倒伏性的关系. 草业学报, 2018, 27(9): 85-94.

Ren S M, Deng Y C, Wen F J, Liu M J, Yuan X Q, Sajad H, Pu Q 
M, Liu W G, Yang W Y. Effects of intercropping on the metabolism of carbon and nitrogen of soybean at the seedling stage and its relationship with lodging. Acta Pratac Sin, 2018, 27(9): 85-94 (in Chinese with English abstract).

[52] 黄琳琳. 干旱胁迫和不同氮素水平对苹果根系氮素吸收和代 谢的影响研究. 西北农林科技大学博士学位论文, 陕西杨凌, 2018.

Huang L L. Effects of Drought Stress and Different Nitrogen
Levels on Nitrogen Uptake and Metabolism in Apple Roots. PhD Dissertation of Northwest A\&F University, Yangling, Shaanxi, China, 2018 (in Chinese with English abstract).

[53] Zhang J, Shi Y, Zhang X, Du H, Xu B, Huang B. Melatonin suppression of heat-induced leaf senescence involves changes in abscisic acid and cytokinin biosynthesis and signaling pathways in perennial ryegrass (Lolium perenne L.). Environ Exp Bot, 2017, 138: 36-45. 